\title{
The inflammatory response to extracorporeal membrane oxygenation (ECMO): a review of the pathophysiology
}

\author{
Jonathan E. Millar ${ }^{1,3^{*}}$, Jonathon P. Fanning ${ }^{1}$, Charles I. McDonald ${ }^{1}$, Daniel F. McAuley ${ }^{2}$ and John F. Fraser ${ }^{1}$
}

\begin{abstract}
Extracorporeal membrane oxygenation (ECMO) is a technology capable of providing short-term mechanical support to the heart, lungs or both. Over the last decade, the number of centres offering ECMO has grown rapidly. At the same time, the indications for its use have also been broadened. In part, this trend has been supported by advances in circuit design and in cannulation techniques. Despite the widespread adoption of extracorporeal life support techniques, the use of ECMO remains associated with significant morbidity and mortality. A complication witnessed during ECMO is the inflammatory response to extracorporeal circulation. This reaction shares similarities with the systemic inflammatory response syndrome (SIRS) and has been well-documented in relation to cardiopulmonary bypass. The exposure of a patient's blood to the non-endothelialised surface of the ECMO circuit results in the widespread activation of the innate immune system; if unchecked this may result in inflammation and organ injury. Here, we review the pathophysiology of the inflammatory response to ECMO, highlighting the complex interactions between arms of the innate immune response, the endothelium and coagulation. An understanding of the processes involved may guide the design of therapies and strategies aimed at ameliorating inflammation during ECMO. Likewise, an appreciation of the potentially deleterious inflammatory effects of ECMO may assist those weighing the risks and benefits of therapy.
\end{abstract}

Keywords: Extracorporeal membrane oxygenation, ECMO, Inflammation, SIRS, Coagulation

\section{Background}

Extracorporeal membrane oxygenation (ECMO) is a technology capable of providing short-term mechanical support to the heart, lungs or both. Despite having first been employed clinically in the 1970s [1], the more widespread use of ECMO in critically ill adult patients is a recent phenomenon [2]. Over the last decade, the number of centres offering ECMO has grown rapidly. At the same time, the indications for ECMO in adults have expanded beyond acute severe respiratory and cardiac failure [3] to include extracorporeal cardiopulmonary resuscitation (ECPR) [4] and as a bridge to lung transplantation [5]. Due to its origins, the use of ECMO is much better established in neonatal and paediatric populations [6]. In fact, neonatal ECMO for respiratory

\footnotetext{
* Correspondence: j.millar@doctors.org.uk

${ }^{1}$ Critical Care Research Group, University of Queensland, Brisbane, Australia

${ }^{3}$ Critical Care Research Group, The Prince Charles Hospital, Rode Road,

Chermside, Queensland 4032, Australia

Full list of author information is available at the end of the article
}

failure accounts for $43 \%$ of the Extracorporeal Life Support Organisation (ELSO) registry, comprising 25 years of records of paediatric and adult patients undergoing ECMO [7].

Survival rates in neonates and children supported with ECMO, especially in cases of respiratory failure, are generally high [8]. For adults, it is difficult to quantify the mortality of patients undergoing ECMO. Several studies have varied in their reported mortalities based on indication and modality $[8,9]$, ranging from $76 \%$ in one cohort undergoing ECMO and dialysis [10] to $37 \%$ in a mixed veno-venous (VV)/veno-arterial (VA) ECMO group [11]. The ELSO registry, between 1989 and 2014, reports mortalities for respiratory and cardiac ECMO, of 57\% and $41 \%$ respectively [7]. In addition, there are a number of complications that may occur, any of which is capable of inflicting serious morbidity. These can be broadly separated into those related to the ECMO device (e.g., oxygenator or pump malfunction, circuit clotting, cannula issues) and physiological complications (e.g., bleeding, 
haemolysis, and infection). In this review, we examine the pathophysiology of one less well-recognised complication, the inflammatory response to ECMO.

\section{The inflammatory response to ECMO}

The initiation of ECMO is associated with an immediate and complex inflammatory reaction, similar to that seen in systemic inflammatory response syndrome (SIRS) [12]. At that moment when the patient's blood first comes into contact with the foreign surface of the extracorporeal circuit, a variety of coagulative and inflammatory cascades are activated (Fig. 1). Levels of pro-inflammatory cytokines rise rapidly [13-19], which, in association with activation of the complement and contact systems [20-25], results in leukocyte activation [26-28]. This innate immune response, if severe, persistent or unchecked by a compensatory anti-inflammatory response (CARS) [29], may lead to endothelial injury, disrupted microcirculation, and endorgan dysfunction [30-35]. Despite major improvements in pump and circuit design, oxygenators and the advent of heparin-bonded surfaces, the SIRS response to ECMO remains a clinical concern. While a large volume of work has been directed towards elucidating and targeting the inflammatory response to cardiopulmonary bypass (CPB) [36-38], a closely related form of extracorporeal circulation, much less has been devoted to studying the inflammatory response to ECMO.

\section{Differences between ECMO and CPB}

ECMO and CPB are closely related and share several similarities. Both techniques generate a biomaterialinduced inflammatory response in patients. Despite this, there are important distinctions between ECMO and CPB (Table 1), of which anyone attempting to infer from one to the other must be aware.

The most obvious distinction between ECMO and $\mathrm{CPB}$ is in the duration of support provided. CPB is commonly employed for only minutes to hours to facilitate a surgical procedure. Conversely, ECMO, used in patients with severe organ failure, can be prolonged for weeks to months. This difference in duration requires a different approach to anticoagulation. During CPB, loading doses of unfractionated heparin between 300 and $500 \mathrm{U} / \mathrm{kg}$ may be used [39], versus $40-80 \mathrm{U} / \mathrm{kg}$ during ECMO [40]. Upon the completion of CPB, protamine sulphate is administered to reverse the effects of heparin, a practice which is avoided during and at the conclusion of ECMO. This is an important distinction, given that the formation of protamine-heparin complexes is known to exacerbate the inflammatory response (via activation of the classical and lectin complement pathways) [41, 42].

Hypothermia is mandatory during $\mathrm{CPB}$, but not commonly employed during ECMO. Likewise, haemodilution, which may also be employed during $\mathrm{CPB}$, is not seen to the same degree during ECMO. Large observational studies have demonstrated an association between the lowest haematocrit recorded during $\mathrm{CPB}$ and postoperative mortality [43]. One suggested explanation for this is that haemodilution leads to increased neutrophil activation [44].

As part of the surgical nature of conventional $\mathrm{CPB}$, cardiotomy suctioning, venting of blood and venous reservoirs are incorporated into circuits. This introduces a blood-air interface. Multiple studies have detected higher levels of pro-inflammatory cytokines in cardiotomysuctioned blood and, in some instances, lower levels of anti-inflammatory cytokines, such as IL-10 [45-47]. The absence of an air/blood interface during ECMO may be a factor in reducing the inflammatory response.

Commonly, perfusion during CPB is non-pulsatile [48]. During VA-ECMO, depending on the residual function of the native heart, varying degrees of pulsatile flow are generated in the face of retrograde arterial perfusion by the ECMO system. This is not the case in VV-ECMO, which uses an "in series configuration, relying on the native heart for systemic perfusion [49]. Evidence from CPB suggests that pulsatile flow during extracorporeal circulation may act to reduce the inflammatory response [50]. It has been hypothesised that this may be due to the ability of pulsatile perfusion to better sustain the functional state of the microcirculation [51].

Contrary to ECMO, CPB involves inflicting an ischaemiareperfusion injury [36]. Clamping of the aorta during surgery renders the heart, and to a large extent the lungs, ischaemic. At the completion of surgery, this clamp is removed and both organs undergo a period of reperfusion. Each phase causes a significant inflammatory reaction. In some patients this may prove significant, leading to the onset of lung ischaemia-reperfusion injury or so-called pump lung [52].

Finally, there are clear patient differences. The majority of patients undergoing $\mathrm{CPB}$ will have chronic disease (often severe), but are unlikely to be acutely unwell at the time of the procedure. Conversely, those undergoing ECMO are usually critically ill.

\section{The pathophysiology of inflammation during ECMO}

The inflammatory response caused by ECMO occurs as a reaction to the exposure of blood to the extracorporeal circulation. Both systemic and cellular factors initiate and propagate the SIRS-like cascade. These include several humoral and cellular systems, most notably the contact, intrinsic and extrinsic coagulation, and the complement systems and endothelial cells, leukocytes, platelets and cytokines. Here we will consider each in turn, although it should be borne in mind that these systems are largely interdependent and still not fully understood. 


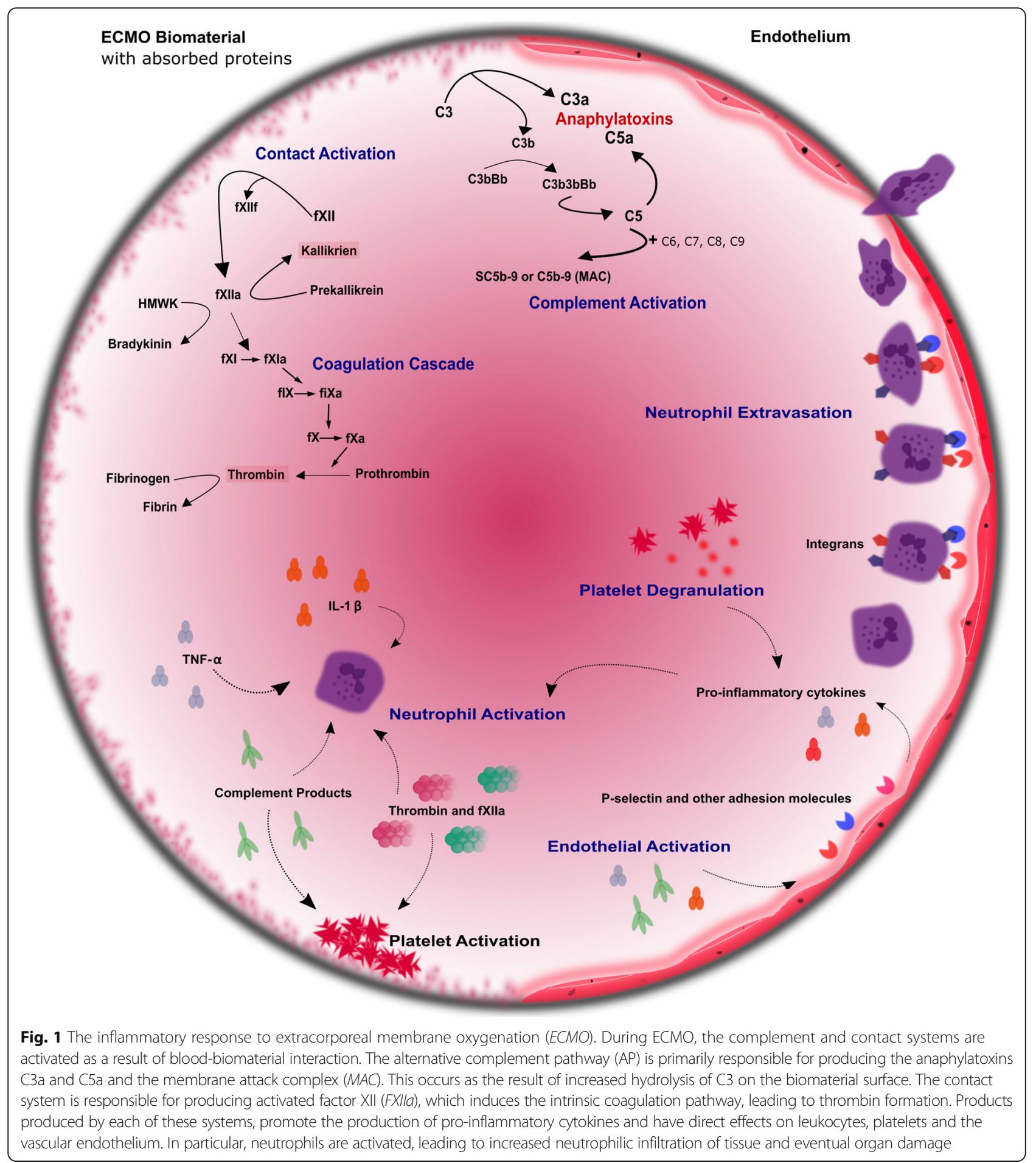

\section{The interplay between coagulation and inflammation}

The contact system

The contact system is composed of several associated plasma proteins: factor XII (Hageman factor), factor XI, high molecular weight kininogen (HMWK) and prekallikrein (Fletcher factor). When blood, in which these proteins are circulating, comes into contact with the extracorporeal circulation, factor XII is cleaved into two proteases: factor XIIa and factor XIIf. Factor XIIa converts prekallikrein into active kallikrein and HMWK into bradykinin (Fig. 1). This is a rapid process, with Factor XIIa activity in the ECMO circuit reaching maximal levels within 10 minutes of initiation [53]. In addition to 
Table 1 Key differences between extracorporeal membrane oxygenation (ECMO) and cardiopulmonary bypass (CPB)

\begin{tabular}{|c|c|c|}
\hline & ECMO & $\mathrm{CPB}$ \\
\hline Duration & Days to weeks & Minutes to hours \\
\hline Anticoagulation & Low-dose heparin & High-dose heparin \\
\hline $\begin{array}{l}\text { Reversal of } \\
\text { anticoagulation }\end{array}$ & Not used & Protamine administration \\
\hline Haemodilution & $\begin{array}{l}\text { Yes - to a lesser } \\
\text { degree than CPB }\end{array}$ & Yes \\
\hline Hypothermia & No & Yes \\
\hline Air-blood interface & No - closed circuit & $\begin{array}{l}\text { Yes - some closed variants } \\
\text { exist }\end{array}$ \\
\hline Pulsatility & $\begin{array}{l}\text { Variable, dependent } \\
\text { on mode }\end{array}$ & Non-pulsatile \\
\hline
\end{tabular}

their role promoting coagulation, kallikrein and bradykinin drive inflammation. Kallikrein production during ECMO is known to directly activate neutrophils [54]. More recently, neutralisation of factor XIIa using a novel inhibitory antibody has been shown to reduce inflammation in ex-vivo and animal models of ECMO [55].

Bradykinin has pleiotropic effects, which include stimulating the release of nitric oxide, tumour necrosis factor-alpha (TNF- $\alpha$ ) and IL-10 [56]. Little is known about bradykinin activity during ECMO, although CPB is associated with dramatically elevated levels [57]. A major contributory factor in this is that the lungs, bypassed during $\mathrm{CPB}$, are the major site of bradykinin inactivation. This is not likely to be a comparable issue during VV-ECMO, but may play a role in a VA-ECMO configuration.

\section{Intrinsic and extrinsic coagulation}

Contact system activation eventually leads to triggering of the intrinsic coagulation pathway. Factor XIIa, formed as a product of contact activation, activates factor XI to XIa. In the following step, factor XIa converts factor IX to IXa, which in turn activates factor X. This is the intrinsic coagulation pathway (Fig. 1). Conversion of factor $\mathrm{X}$ is the first common step in the coagulation cascade between the intrinsic and extrinsic pathways. The extrinsic pathway was traditionally felt to play a lesser role during extracorporeal circulation, due in part to the requirement for tissue injury and the subsequent exposure of tissue factor (TF), although TF may be present within extracorporeal circuits, in pro-inflammatory conditions, despite the absence of tissue injury [58]. The ability of activated complement to induce the expression of TF by monocytes may be one way in which this effect is mediated [59, 60]. Alternatively, Szotowski et al. have described the ability of TNF- $\alpha$ and IL- 6 to induce the endothelial cell expression of soluble TF [61].
By whichever means the common pathway is arrived at, activated factor $\mathrm{X}$ (FXa) converts prothrombin to thrombin, which then cleaves fibrinogen to fibrin, resulting in subsequent clot formation. In addition to its role in coagulation, thrombin plays a major part in inflammation. It is known to increase the expression of P-selectin and E-selectin by endothelial cells, increasing neutrophil adherence and activation [62, 63]. Thrombin also induces endothelial cells to produce platelet activating factor (PAF), another potent activator of neutrophils [64], and directly influences neutrophils to express proinflammatory cytokines [65]. Attempts have been made to limit thrombin generation during extracorporeal circulation using biocompatible circuitry. Several coating materials are utilised in commercially available ECMO circuits, most commonly heparin and heparin-like compounds. Studies have demonstrated reduced levels of thrombin when heparin-bonded minimal extracorporeal circulation systems (MECC) are used, and these are functionally similar to ECMO $[66,67]$.

\section{Platelets}

In addition to their role in haemostasis, platelets are a key mediator of inflammation during ECMO [68]. At the very outset of extracorporeal circulation, activated platelets begin to adhere to fibrinogen absorbed by the circuit. The activation of platelets largely occurs in response to thrombin generation, although complement activation [69] and the physical characteristics of the circuit also play a part. Adherent platelets undergo alterations in their shape and release their granular content (as do some circulating platelets). Platelet granules contain a variety of soluble mediators, including chemokines, pro-inflammatory cytokines, proteases, adhesion factors, growth factors, angiogenic factors and haemostatic factors [70, 71]. Bound platelets are also capable of forming leukocyte conjugates, predominantly with monocytes, but also neutrophils [72]. This platelet-leukocyte interaction induces leukocytes to secrete pro-inflammatory cytokines and monocytes to express TF [73, 74]. During ECMO, these processes appear to be time-dependent, with a progressive increase in activity noted in one study [68].

\section{ECMO and the complement system}

The complement system acts at the forefront of the innate immune response and, as such, is one of the body's first host defences to be activated when ECMO is initiated [23]. An interactive cascade of over 30 complementrelated proteins acts to destroy and remove foreign substances identified as "non-self", in addition to substances released from damaged cells. Complement achieves this either by direct cell lysis, by producing a trans-membrane pore known as a membrane attack complex (MAC), or by modulating leukocytes via opsonisation or the production 
of pro-inflammatory anaphylatoxins [75]. The complement cascade may be activated by any or all of three pathways: the classical pathway $(\mathrm{CP})$, the alternative pathway (AP), and the lectin pathway (LP).

Across the three pathways, the first common step in the cascade is the cleavage of $\mathrm{C} 3$ to $\mathrm{C} 3 \mathrm{a}$ and C3b (Fig. 1). In the alternative pathway, subsequent steps result in $\mathrm{C} 5$ being cleaved to form $\mathrm{C} 5 \mathrm{a}$ and $\mathrm{C} 5 \mathrm{~b}$. The two resulting molecules have distinct effects. C5a is a potent proinflammatory mediator ( $\mathrm{C} 3 \mathrm{a}$ is also an anaphylatoxin, albeit not as potent) with several abilities in vivo, including increasing leukocyte recruitment, increasing vascular permeability and inciting further inflammatory mediator release [76]. On the other hand, C5b progresses through several steps to produce C5b-9 (the MAC). Given its antibody independence, it is thought that the AP is the principal means of complement activation during extracorporeal circulation (ECC), occurring as a result of blood contacting the foreign material of the circuit [77].

Although the complement response to $\mathrm{CPB}$ has been well-described [78-81], the role of complement activation during ECMO is, by contrast, poorly defined. The few available studies date from the 1990s and were conducted using the much less advanced pump and circuit technology that was available to investigators at that time [19,21-25]. This is important, as improvements in both circuitry and pump technology have likely had a beneficial effect on the levels of complement activation seen during ECMO. Studies on CPB have shown us that the use of centrifugal pumps, now ubiquitous in modern ECMO, reduces complement activation $[82,83]$. In addition, the use of contemporary heparinbonded circuits has also been shown to reduce complement activation [84]. Studies have examined complement activation in ex-vivo models of ECMO [20, 22, 24], neonatal ECMO [20, 23, 25] and in adult patients [21]. In keeping with $\mathrm{CPB}$, all of these studies revealed rapid elevations in the levels of complement factors during ECMO, with peaks occurring within 1 to 2 hours.

As previously stated, a key differentiator between the extracorporeal circulation of $\mathrm{CPB}$ and $\mathrm{ECMO}$ is their relative duration. This effect has been described by several authors. In two adult patients on ECMO for acute respiratory distress syndrome (ARDS), Vallhonrat et al., described rapid elevations in the levels of $\mathrm{C} 3 \mathrm{~b}$ and terminal complement complex (TCC) (fluid-phase MAC), which were evident within 15 minutes of commencing ECMO. These levels peaked by 60 minutes and had begun to fall by 180 minutes, reaching near-baseline levels at 2 days. Of note was the failure to demonstrate any significant elevation in $\mathrm{C} 4 \mathrm{~d}$, a classical pathway marker [21]. In neonates, Graulich et al. detected peaks of C3a at 1 hour and of C5a and TCC at 2 hours. However, contrary to what Vallhonrat et al. observed, TCC levels did not return to baseline [20].
Ex-vivo studies of complement activation in ECMO have almost universally failed to uncover peak or falling levels of complement products. Using heparinised fresh whole human blood in an ex-vivo circuit, Moen et al. recorded levels of $\mathrm{C} 3$ activation products and TCC continuing to rise after 72 hours of ECMO [22]; this points towards the presence of a negative feedback mechanism in-vivo, which acts to limit inappropriate complement activation. Bergman et al. employed an ex-vivo model of ECMO, with a mixture of non-heparinised citrated fresh human blood and Ringer's solution, to examine the influence of complement activation during ECMO on blood cell rheological properties. Close correlation between the levels of complement factors, particularly C5a and TCC, and white cell deformability were noted, leading the authors to conclude that high levels of complement activation during ECMO may play a part in the rheological deterioration of blood cells [24].

\section{ECMO, the endothelium and leukocytes}

\section{Endothelial cell activation}

Endothelial dysfunction in the critically ill is an important marker of poor outcome [85, 86]. Even without being in direct contact with the extracorporeal circuit, the vascular endothelium plays a crucial role in the inflammatory response during ECMO. In a fashion similar to that of SIRS, the generation of inflammatory mediators in response to extracorporeal circulation results in the widespread activation of the endothelium, with a subsequent alteration in endothelial cell gene expression [87]. This occurs in response to a number of cytokines, complement products and reactive oxygen species (ROS). Activated endothelial cells in turn secrete proinflammatory cytokines and increase their expression of adhesion molecules, leading to the increased transmigration of leukocytes.

Early activation of the endothelium occurs in response to complement products [88]. These factors act on endothelial cells to induce the upregulation of Pselectin. The expression of P-selectin on the endothelial surface in turn spurs the recruitment of activated leukocytes. This process occurs rapidly, as P-selectin exists pre-stored in the cytoplasm of endothelial cells. However, complement-mediated endothelial activation is short-lived, thus, it is an increase in the circulating levels of pro-inflammatory cytokines that is responsible for the later activation of the endothelium [87]. TNF- $\alpha$ and IL-1 $\beta$ are perhaps the most influential cytokines in this process [36]. Endothelial activation by either mechanism results in the recruitment, "rolling", firm adhesion and trans-migration of activated neutrophils. Neutrophilic infiltration is thought to be responsible for the end-organ damage associated with ECMO [15]. 


\section{Neutrophils and monocytes}

Neutrophils are activated by several mechanisms triggered by ECMO. This response shares certain similarities with the pathogenesis of ARDS [89]. Complement contributes to the almost instantaneous activation of neutrophils on the commencement of extracorporeal circulation [90]. Using a simulated model of ECC, Rinder et al. have described the importance of C5a and TCC in this process, showing that the addition of a human monoclonal antibody directed at C5 significantly inhibits neutrophil activation [91].

Ex-vivo models of ECMO show that the activation of neutrophils increases dramatically within the first $30 \mathrm{mi}$ nutes, peaks within the first few hours, and declines thereafter. Of note from these studies, is the observation that leukocytes do not adhere to the circuitry [26, 27]. Once activated, neutrophils degranulate, releasing stores of cytotoxic enzymes, such as neutrophil elastase, myeloperoxidases and lysozymes. In addition, via a "respiratory burst", neutrophils are also capable of releasing cytotoxic ROS. It is via these mechanisms, both within the vasculature and after trans-migration into the tissues that neutrophils act as the effectors of organ damage during ECMO [92]. The site of neutrophil activation during ECMO is likely to be multifocal, although in one experimental model of ECMO the fundamental role of the oxygenator was described [14]. During CPB, concentrations of neutrophil elastase, IL-8 and neutrophils are significantly elevated in bronchoalveolar lavage fluid; furthermore, these levels are correlated with the patients' arterial partial pressure of oxygen $\left(\mathrm{PaO}_{2}\right) /$ fraction of inspired oxygen $\left(\mathrm{FiO}_{2}\right)$ ratios [93].

While no comparable study has been conducted in adults on ECMO, early studies, performed in neonates on ECMO, demonstrated an association between neutrophil activation and pulmonary deterioration [23, 27]. Increased neutrophil margination into several tissues, particularly the lungs, has been described during ECMO, both in animal models and in neonates [14, 15, 30, 94]. Overall, neutrophil numbers increase after the initiation of extracorporeal circulation [95] and neutrophil function appears to be preserved [25, 28]. This is despite the reported adverse effects of ECMO on leukocyte rheology [96].

Monocytes are also activated in response to ECMO [26], though this appears to occur more slowly than the activation of neutrophils [36]. When appropriately stimulated, monocytes may secrete a number of pro-inflammatory cytokines [97].

\section{ECMO and cytokines}

The initiation of ECMO results in the production of a variety of pro-inflammatory and anti-inflammatory cytokines. These small proteins have a variety of roles in cell signalling and are important mediators of the innate immune response. There is little evidence to support a single "master" cytokine in this process. This has implications in selecting potential therapeutic interventions. While interventions aimed at single cytokine targets are unlikely to overcome the redundancy in the system, more broadbased approaches, such as cell therapy, appear to have significant potential. We subsequently describe the most studied cytokines with respect to ECMO.

TNF- $\alpha$ is produced by a range of cell types in response to an inflammatory stimulus. TNF- $\alpha$ has pleiotropic effects on a variety of tissues; but, perhaps most importantly, it is a potent activator of neutrophils [98]. Furthermore, it induces the expression of adhesion molecules by endothelial cells, enhancing the margination of neutrophils. TNF- $\alpha$ can also stimulate macrophage phagocytosis, enhance the expression of prostaglandins and increase the formation of thrombin [99]. TNF- $\alpha$ acts as a negative inotrope at the macrocirculatory level. During ECMO, it is thought that a large proportion of early TNF- $\alpha$ release originates from pre-formed stores in mast cells. In a porcine ECMO study, McIlwain et al. identified gut mucosal mast cells as the key contributor to early TNF- $\alpha$ release. During the first 2 hours of ECMO, increased plasma TNF- $\alpha$ was not associated with increased tissue synthesis. This, combined with a decreased level of TNF- $\alpha$ found in gut mucosa, led the authors to hypothesise that mast cell degranulation, in response to complement activation, is the likely mechanism by which TNF- $\alpha$ concentrations are elevated [15]. Higher levels of TNF- $\alpha$ have been associated with non-survival in neonates undergoing ECMO $[23,27]$.

Interleukin-6 is a complicated cytokine, with both proand anti-inflammatory actions. Whilst promoting the acute phase reaction, expansion and activation of T-cells and the differentiation of B cells, IL-6 may also downregulate the expression of other pro-inflammatory cytokines, as well as up-regulate the expression of the anti-inflammatory cytokines [100]. Studies have reported consistent elevations in IL-6 levels during ECMO [15, 18, 30, 32, 101]. IL-6 levels in the lungs have also been shown to rise after VV-ECMO in an animal model, where they were associated with parenchymal damage [30]. Interestingly, given that IL-6 has a key role initiating the acute phase response and its concentration is thus usually closely coupled to C-reactive protein (CRP) production, McIlwain et al. failed to demonstrate any link between the two during porcine ECMO [15]. In a combined study by Risnes et al., involving children and adults supported with ECMO, levels of IL-6 were inversely associated with survival, with a clear divergence in IL-6 concentrations between survivors and nonsurvivors after two days of ECMO support: survivors effectively normalised their IL-6 levels whilst those who died maintained a persistent elevation. This was not 
observed to be the case for other cytokines, such as IL1- $\beta$, IL-8 or IL-10 [102].

IL-8 is a potent neutrophil activator and a chemoattractant for neutrophils, basophils and T-lymphocytes. Studies using simulations and animal models and in neonates have demonstrated rapid elevations of IL-8 after ECMO commences $[15,18,27]$. Alterations in IL-8 concentration appear to follow a temporal trend similar to TNF- $\alpha$, with increases noted within the first 15 minutes of ECMO $[15,27]$.

A number of other cytokines have also been implicated in the inflammatory response to ECMO and extracorporeal circulation. Of note is that low levels of the anti-inflammatory cytokine IL-10 (at the time of ECMO initiation) have been associated with poor survival [103].

\section{Future directions}

In the last decade, ECMO technology has improved dramatically. This has facilitated its uptake in an increasing number of centres for an ever-growing range of indications. Ongoing research into anticoagulation, servo control and membrane lung construction will further improve the safety and efficacy of ECMO [104]. Additional research (pre-clinical and clinical) is required to assess the impact of ECMO-induced inflammation on clinically meaningful outcomes. This work will inform the requirement for novel anti-inflammatory therapies that could be used during ECMO. In future, when designing strategies to minimise the inflammatory response to ECMO, several experimental treatments appear to have potential, in particular, the use of Factor XII inhibitors and mesenchymal stromal cell (MSC) therapy.

Currently, there is substantial interest in targeting factor XII as a novel means of anticoagulation [105]. The use of a factor XII inhibitor in this setting is attractive given the potential to reduce, or eliminate, the risk of thrombosis without encountering the bleeding risk associated with current anticoagulants. A beneficial side-effect would be the inhibition of contact-mediated inflammation involving the activation of factor XII. A recombinant human antibody, 3 F7, which inhibits FXIIa, has been successfully tested in a rabbit model of VA-ECMO [55]. Any future work will need to demonstrate the safety and efficacy of factor XII inhibitors in a large animal model of ECMO, using contemporary clinical ECMO equipment, before progression to human studies.

MSC therapy is being investigated as a treatment for a number of acute inflammatory conditions. MSCs are multipotent adult stem cells found in most tissues of mesodermal origin, such as bone marrow [106]. MSCs have attracted attention due to their immunomodulatory effects. In-vitro MSCs have been shown to influence both the adaptive and innate immune response to infection and inflammation; this ability is bi-directional, that is to say, MSCs may either promote or ameliorate inflammation dependent on the contemporary milieu [107]. MSCs have been studied in a pre-clinical model of $\mathrm{CPB}$ as a means of reducing the harm associated with ischaemia-reperfusion injury [108]. Here, infusion of human MSCs significantly reduced the levels of inflammatory cytokines within 3 hours. Given their ability to influence the innate immune response at a range of points in the cascade and in a manner consistent with the local environment, MSCs have the potential to be efficacious in the setting of ECMO-induced inflammation.

\section{Conclusion}

The inflammatory response to ECMO is complex and multi-faceted. It remains unclear whether this excess inflammation is all deleterious, or if it has potential benefits to the host. In summary, it arises principally due to the contact and complement systems becoming activated as a result of blood exposure to the extracorporeal circuit. The combination of a sustained innate immune response and the pro-inflammatory aspects of coagulation result in "pan-endothelial" injury, with leukocyte activation and the production of pro-inflammatory mediators. This ultimately ends in a systemic inflammatory response and endorgan damage.

Whilst this process shares a number of similarities with the inflammatory response witnessed during $\mathrm{CPB}$, there are also a number of important distinctions. Given the recent increase in the use of ECMO, there is a relative paucity of data on the inflammatory response that it induces. This is compounded by the fact that many of the available studies were conducted prior to the introduction of modern innovations in ECMO technology. Mechanistic and outcome information from adult patients is absent. Clearly all patients supported on ECMO experience some degree of inflammatory response to ECMO, but currently there is no physiological rationale to explain the extreme variation seen in the magnitude of the patients' responses to that inflammation, nor their clinical course. Whilst it is undoubtedly difficult to isolate the relative contribution of specific components of the inflammatory response (proinflammatory and CARS) to outcomes after ECMO, failure to do so may lead to a missed opportunity for intervention. The first step towards addressing this deficit is to not only improve our understanding of the basic science underpinning the inflammatory response induced by modern ECMO, but to adopt minimal reporting criteria for the inflammatory response during human ECMO studies, in a manner similar to that proposed for CPB [109]. Such studies should be conducted in models that are relevant, using technology that is in contemporary clinical use. A more detailed understanding of the underlying processes will allow us to better investigate potential therapies and design future clinical studies. 


\section{Abbreviations}

AP: Alternative (complement) pathway; ARDS: Acute respiratory distress syndrome; CABG: Coronary artery bypass grafting; CARS: Compensatory anti-inflammatory response syndrome; CP: Classical (complement) pathway; CPB: Cardiopulmonary bypass; ECC: Extracorporeal circulation; ECMO: Extracorporeal membrane oxygenation; ECPR: Extracorporeal cardiopulmonary resuscitation; ELSO: Extracorporeal Life Support Organisation; $\mathrm{FiO}_{2}$ : Fraction of inspired oxygen; HMWK: High molecular weight kininogen; IL: Interleukin; LP: Lectin (complement) pathway; MAC: Membrane attack complex; PAF: Platelet activating factor; $\mathrm{PaO}_{2}$ : Arterial partial pressure of oxygen; ROS: Reactive oxygen species; SIRS: Systemic inflammatory response syndrome; TCC: Terminal complement complex TF: Tissue factor; TNF-a: Tumour necrosis factor alpha; VA: Veno-arterial; W: Veno-venous

\section{Acknowledgements}

The authors would like to recognize the financial assistance provided by the National Health and Medical Research Council (NHMRC) (APP1079421). The contents are solely the responsibility of the authors and do not reflect the views of the NHMRC.

\section{Funding}

Publication of this article was funded by the National Health and Medical Research Council (Australia) Centre for Research Excellence in Advanced Cardio-respiratory Therapies Improving OrgaN Support (CREACTIONS).

\section{Availability of data and materials}

Not applicable.

\section{Authors' contributions}

JEM, DFM and JFF conceived the review. JEM wrote the first draft of the manuscript. JPF and CIM edited the draft and rewrote individual sections. All authors participated in the final edit and in review of the manuscript. All authors read and approved the final manuscript.

\section{Authors' information}

Not applicable.

\section{Competing interests}

The authors declare that they have no competing interests.

\section{Consent for publication}

Not applicable.

\section{Ethics approval and consent to participate}

Not applicable.

\section{Author details}

${ }^{1}$ Critical Care Research Group, University of Queensland, Brisbane, Australia. ${ }^{2}$ Wellcome-Wolfson Centre for Experimental Medicine, Queen's University Belfast, Belfast, UK. ${ }^{3}$ Critical Care Research Group, The Prince Charles Hospital, Rode Road, Chermside, Queensland 4032, Australia.

\section{Published online: 28 November 2016}

\section{References}

1. Hill JD, O'Brien TG, Murray JJ, Dontigny L, Bramson ML, Osborn JJ, Gerbode F. Prolonged extracorporeal oxygenation for acute post-traumatic respiratory failure (shock-lung syndrome). Use of the Bramson membrane lung. N Engl J Med. 1972;286(12):629-34.

2. Sauer CM, Yuh DD, Bonde P. Extracorporeal membrane oxygenation use has increased by $433 \%$ in adults in the United States from 2006 to 2011. ASAIO J. 2015;61(1):31-6

3. Shekar K, Mullany DV, Thomson B, Ziegenfuss M, Platts DG, Fraser JF. Extracorporeal life support devices and strategies for management of acute cardiorespiratory failure in adult patients: a comprehensive review. Crit Care. 2014;18(3):219

4. Mosier JM, Kelsey M, Raz Y, Gunnerson KJ, Meyer R, Hypes CD, Malo J, Whitmore SP, Spaite DW. Extracorporeal membrane oxygenation (ECMO) for critically ill adults in the emergency department: history, current applications, and future directions. Crit Care. 2015;19:431.
5. Schechter MA, Ganapathi AM, Englum BR, Speicher PJ, Daneshmand MA, Davis RD, Hartwig MG. Spontaneously breathing extracorporeal membrane oxygenation support provides the optimal bridge to lung transplantation. Transplantation. 2016;100(2):2699-2704.

6. Robinson S, Peek G. The role of ECMO in neonatal and paediatric patients. Paediatr Child Health. 2015:25(5):222-7.

7. Clark JB, Wang S, Palanzo DA, Wise R, Baer LD, Brehm C, Undar A. Current techniques and outcomes in extracorporeal life support. Artif Organs. 2015; 39(11):926-30.

8. Gray BW, Haft JW, Hirsch JC, Annich GM, Hirschl RB, Bartlett RH. Extracorporeal life support: experience with 2,000 patients. ASAIO J. 2015;61(1):2-7.

9. Zangrillo A, Landoni G, Biondi-Zoccai G, Greco M, Greco T, Frati G, Patroniti N, Antonelli M, Pesenti A, Pappalardo F. A meta-analysis of complications and mortality of extracorporeal membrane oxygenation. Crit Care Resusc. 2013:15(3):172-8.

10. Tsai CW, Lin YF, Wu VC, Chu TS, Chen YM, Hu FC, Wu KD, Ko WJ. SAPS 3 at dialysis commencement is predictive of hospital mortality in patients supported by extracorporeal membrane oxygenation and acute dialysis. Eur J Cardiothorac Surg. 2008;34(6):1158-64.

11. Aubron C, Cheng AC, Pilcher D, Leong T, Magrin G, Cooper DJ, Scheinkestel $C$, Pellegrino V. Factors associated with outcomes of patients on extracorporeal membrane oxygenation support: a 5-year cohort study. Crit Care. 2013;17(2):R73.

12. Davies MG, Hagen PO. Systemic inflammatory response syndrome. Br J Surg. 1997:84(7):920-35.

13. Wang S, Krawiec C, Patel S, Kunselman AR, Song J, Lei F, Baer LD, Undar A. Laboratory evaluation of hemolysis and systemic inflammatory response in neonatal nonpulsatile and pulsatile extracorporeal life support systems. Artif Organs. 2015;39(9):774-81

14. Rungatscher A, Tessari M, Stranieri C, Solani E, Linardi D, Milani E, Montresor A, Merigo F, Salvetti B, Menon T, et al. Oxygenator is the main responsible for leukocyte activation in experimental model of extracorporeal circulation: a cautionary tale. Mediators Inflamm. 2015;2015:484979.

15. MclLwain RB, Timpa JG, Kurundkar AR, Holt DW, Kelly DR, Hartman YE, Neel ML, Karnatak RK, Schelonka RL, Anantharamaiah GM, et al. Plasma concentrations of inflammatory cytokines rise rapidly during ECMO-related SIRS due to the release of preformed stores in the intestine. Lab Invest. 2010:90(1):128-39.

16. Mildner RJ, Taub N, Vyas JR, Killer HM, Firmin RK, Field DJ, Kotecha S. Cytokine imbalance in infants receiving extracorporeal membrane oxygenation for respiratory failure. Biol Neonate. 2005;88(4):321-7.

17. Golej J, Winter P, Schoffmann G, Kahlbacher H, Stoll E, Boigner H, Trittenwein G. Impact of extracorporeal membrane oxygenation modality on cytokine release during rescue from infant hypoxia. Shock. $2003 \cdot 20(2) \cdot 110-5$

18. Adrian K, Mellgren K, Skogby M, Friberg LG, Mellgren G, Wadenvik H. Cytokine release during long-term extracorporeal circulation in an experimental model. Artif Organs. 1998;22(10):859-63.

19. Hirthler M, Simoni J, Dickson M. Elevated levels of endotoxin, oxygenderived free radicals, and cytokines during extracorporeal membrane oxygenation. J Pediatr Surg. 1992;27(9):1199-202.

20. Graulich J, Sonntag J, Marcinkowski M, Bauer K, Kossel H, Buhrer C, Obladen $\mathrm{M}$, Versmold HT. Complement activation by in vivo neonatal and in vitro extracorporeal membrane oxygenation. Mediators Inflamm. 2002;11(2):69-73.

21. Vallhonrat $H$, Swinford RD, Ingelfinger JR, Williams WW, Ryan DP, Tolkoff-Rubin N, Cosimi $A B$, Pascual M. Rapid activation of the alternative pathway of complement by extracorporeal membrane oxygenation. ASAIO J. 1999;45(1):113-4.

22. Moen O, Fosse E, Braten J, Andersson C, Fagerhol MK, Venge P, Hogasen K, Mollnes TE. Roller and centrifugal pumps compared in vitro with regard to haemolysis, granulocyte and complement activation. Perfusion. 1994;9(2):109-17.

23. Plotz FB, van Oeveren W, Bartlett $\mathrm{RH}$, Wildevuur $\mathrm{CR}$. Blood activation during neonatal extracorporeal life support. J Thorac Cardiovasc Surg. 1993:105(5):823-32.

24. Bergman P, Friberg G, Liu B, Al-Khaja N, Belboul A, Heideman M, Mellgren G, Roberts D. Blood cell rheologic deterioration by complement activation during experimental prolonged perfusion with membrane oxygenation. Perfusion. 1992:7(1):13-9.

25. Hocker JR, Wellhausen SR, Ward RA, Simpson PM, Cook LN. Effect of extracorporeal membrane oxygenation on leukocyte function in neonates. Artif Organs. 1991;15(1):23-8. 
26. Graulich J, Walzog B, Marcinkowski M, Bauer K, Kossel H, Fuhrmann G, Buhrer C, Gaehtgens P, Versmold HT. Leukocyte and endothelial activation in a laboratory model of extracorporeal membrane oxygenation (ECMO). Pediatr Res. 2000;48(5):679-84.

27. Fortenberry JD, Bhardwaj V, Niemer P, Cornish JD, Wright JA, Bland L. Neutrophil and cytokine activation with neonatal extracorporeal membrane oxygenation. J Pediatr. 1996;128(5 Pt 1):670-8.

28. DePuydt LE, Schuit KE, Smith SD. Effect of extracorporeal membrane oxygenation on neutrophil function in neonates. Crit Care Med. 1993; 21(9):1324-7.

29. Adib-Conquy M, Cavaillon JM. Compensatory anti-inflammatory response syndrome. Thromb Haemost. 2009;101(1):36-47.

30. Shi J, Chen Q, Yu W, Shen J, Gong J, He C, Hu Y, Zhang J, Gao T, Xi F, et al. Continuous renal replacement therapy reduces the systemic and pulmonary inflammation induced by venovenous extracorporeal membrane oxygenation in a porcine model. Artif Organs. 2014;38(3):215-23.

31. He C, Yang S, Yu W, Chen Q, Shen J, Hu Y, Shi J, Wu X, Li J, Li N. Effects of continuous renal replacement therapy on intestinal mucosal barrier function during extracorporeal membrane oxygenation in a porcine model. J Cardiothorac Surg. 2014;9:72.

32. Yimin $H$, Wenkui $Y$, Jialiang $S$, Qiyi $C$, Juanhong $S$, Zhiliang $L$, Changsheng $H$ Ning $L$, Jieshou $L$. Effects of continuous renal replacement therapy on renal inflammatory cytokines during extracorporeal membrane oxygenation in a porcine model. J Cardiothorac Surg. 2013;8:113.

33. Shen J, Yu W, Chen Q, Shi J, Hu Y, Zhang J, Gao T, Xi F, He C, Gong J, et al. Continuous renal replacement therapy (CRRT) attenuates myocardial inflammation and mitochondrial injury induced by venovenous extracorporeal membrane oxygenation (W ECMO) in a healthy piglet model. Inflammation. 2013;36(5):1186-93.

34. Shen J, Yu W, Shi J, Chen Q, Hu Y, Zhang J, Gao T, Xi F, Gong J, He C, et al. Effect of venovenous extracorporeal membrane oxygenation on the heart in a healthy piglet model. J Cardiothorac Surg. 2013;8:163.

35. Chen Q, Yu W, Shi J, Shen J, Hu Y, Gao T, Zhang J, Xi F, Gong J, Li J, et al. The effect of venovenous extra-corporeal membrane oxygenation (ECMO) therapy on immune inflammatory response of cerebral tissues in porcine model. J Cardiothorac Surg. 2013:8:186.

36. Warren OJ, Smith AJ, Alexiou C, Rogers PL, Jawad N, Vincent C, Darzi AW, Athanasiou T. The inflammatory response to cardiopulmonary bypass: part 1mechanisms of pathogenesis. J Cardiothorac Vasc Anesth. 2009;23(2):223-31.

37. Warren OJ, Watret AL, de Wit KL, Alexiou C, Vincent C, Darzi AW, Athanasiou T. The inflammatory response to cardiopulmonary bypass: part 2-anti-inflammatory therapeutic strategies. J Cardiothorac Vasc Anesth. 2009;23(3):384-93.

38. Landis RC, Brown JR, Fitzgerald D, Likosky DS, Shore-Lesserson L, Baker RA, Hammon JW. Attenuating the systemic inflammatory response to adult cardiopulmonary bypass: a critical review of the evidence base. J Extra Corpor Technol. 2014;46(3):197-211.

39. Sniecinski RM, Levy JH. Anticoagulation management associated with extracorporeal circulation. Best Pract Res Clin Anaesthesiol. 2015;29(2): 189-202.

40. Esper SA, Levy JH, Waters JH, Welsby IJ. Extracorporeal membrane oxygenation in the adult: a review of anticoagulation monitoring and transfusion. Anesth Analg. 2014;118(4):731-43.

41. Pagowska-Klimek I, Swierzko AS, Michalski M, Glowacka E, Szala-Pozdziej A, Sokolowska A, Moll M, Krajewski WR, Romak J, Cedzynski M. Activation of the lectin pathway of complement by cardiopulmonary bypass contributes to the development of systemic inflammatory response syndrome after pediatric cardiac surgery. Clin Exp Immunol. 2015;184(2):257-63.

42. Schaub C, Thomas OD, Åkervall Fridh L, Schött U. Protamine dosage effects on complement activation and sonoclot coagulation analysis after cardiac surgery. Cardiovasc Syst. 2013;1(1). http://dx.doi.org/10.7243/2052-4358-1-1.

43. DeFoe GR, Ross CS, Olmstead EM, Surgenor SD, Fillinger MP, Groom RC, Forest RJ, Pieroni JW, Warren CS, Bogosian ME, et al. Lowest hematocrit on bypass and adverse outcomes associated with coronary artery bypass grafting. Northern New England Cardiovascular Disease Study Group. Ann Thorac Surg. 2001;71(3):769-76

44. Gourlay T, Samartzis I, Taylor KM. The effect of haemodilution on bloodbiomaterial contact-mediated CD11b expression on neutrophils: ex vivo studies. Perfusion. 2003;18(2):87-93.

45. Gäbel J, Westerberg M, Bengtsson A, Jeppsson A. Cell salvage of cardiotomy suction blood improves the balance between pro- and anti-inflammatory cytokines after cardiac surgery. Eur J Cardiothorac Surg. 2013;44(3):506-11.
46. Westerberg M, Bengtsson A, Jeppsson A. Coronary surgery without cardiotomy suction and autotransfusion reduces the postoperative systemic inflammatory response. Ann Thorac Surg. 2004;78(1):54-9.

47. Damgaard S, Nielsen CH, Andersen LW, Bendtzen K, Tvede M, Steinbruchel DA Cell saver for on-pump coronary operations reduces systemic inflammatory markers: a randomized trial. Ann Thorac Surg. 2010;89(5):1511-7.

48. Ji B, Ündar A. An evaluation of the benefits of pulsatile versus nonpulsatile perfusion during cardiopulmonary bypass procedures in pediatric and adult cardiac patients. ASAIO J. 2006;52(4):357-61.

49. Massoudy P, Zahler S, Becker BF, Braun SL, Barankay A, Meisner H. Evidence for inflammatory responses of the lungs during coronary artery bypass grafting with cardiopulmonary bypass. Chest. 2001;119(1):31-6.

50. Orime $Y$, Shiono $M$, Hata $H$, Yagi S, Tsukamoto S, Okumura H, Nakata K Kimura S, Hata M, Sezai A, et al. Cytokine and endothelial damage in pulsatile and nonpulsatile cardiopulmonary bypass. Artif Organs. 1999; 23(6):508-12.

51. O'Neill B, McDowell K, Bradley J, Blackwood B, Mullan B, Lavery G, Agus A, Murphy S, Gardner E, McAuley DF. Effectiveness of a programme of exercise on physical function in survivors of critical illness following discharge from the ICU: study protocol for a randomised controlled trial (REVIVE). Trials. 2014;15:146.

52. den Hengst WA, Gielis JF, Lin JY, Van Schil PE, De Windt LJ, Moens AL. Lung ischemia-reperfusion injury: a molecular and clinical view on a complex pathophysiological process. Am J Physiol Heart Circ Physiol. 2010;299(5):H1283-99.

53. Wendel HP, Scheule AM, Eckstein FS, Ziemer G. Haemocompatibility of paediatric membrane oxygenators with heparin-coated surfaces. Perfusion. 1999;14(1):21-8.

54. Wachtfogel YT, Hack CE, Nuijens JH, Kettner C, Reilly TM, Knabb RM, Bischoff $\mathrm{R}$, Tschesche $\mathrm{H}$, Wenzel $\mathrm{H}$, Kucich $U$, et al. Selective kallikrein inhibitors alter human neutrophil elastase release during extracorporeal circulation. Am J Phys. 1995;268(3 Pt 2):H1352-7.

55. Larsson M, Rayzman V, Nolte MW, Nickel KF, Björkqvist J, Jämsä A, Hardy MP, Fries M, Schmidbauer S, Hedenqvist P, et al. A factor Xlla inhibitory antibody provides thromboprotection in extracorporeal circulation without increasing bleeding risk. Sci Transl Med. 2014;6((222):222ra217.

56. Rodell TC, Naidoo Y, Bhoola KD. Role of kinins in inflammatory responses. Clin Immunotherapeutics. 2012;3(5):352-61.

57. Cugno M, Nussberger J, Biglioli P, Giovagnoni MG, Gardinali M, Agostoni A. Cardiopulmonary bypass increases plasma bradykinin concentrations. Immunopharmacology. 1999:43(2-3):145-7.

58. Morgan EN, Pohlman TH, Vocelka C, Farr A, Lindley G, Chandler W, Griscavage-Ennis JM, Verrier ED. Nuclear factor KB mediates a procoagulant response in monocytes during extracorporeal circulation. J Thorac Cardiovasc Surg. 2003;125(1):165-71.

59. Kappelmayer J, Bernabei A, Edmunds LH, Edgington TS, Colman RW. Tissue factor is expressed on monocytes during simulated extracorporeal circulation. Circ Res. 1993;72(5):1075-81.

60. Barstad RM, ØVrum E, Ringdal M-AL, ØYstese R, Hamers MJAG, Veiby OP Rolfsen T, Stephens RW, Sakariassen KS. Induction of monocyte tissue factor procoagulant activity during coronary artery bypass surgery is reduced with heparin-coated extracorporeal circuit. Br J Haematol. 1996;94(3):517-25.

61. Szotowski B, Antoniak S, Poller W, Schultheiss H-P, Rauch U. Procoagulant soluble tissue factor is released from endothelial cells in response to inflammatory cytokines. Circ Res. 2005;96(12):1233-9.

62. Kaplanski G, Fabrigoule M, Boulay V, Dinarello CA, Bongrand P, Kaplanski S, Farnarier C. Thrombin induces endothelial type II activation in vitro: IL-1 and TNF-alpha-independent IL-8 secretion and E-selectin expression. J Immunol. 1997;158(11):5435-41.

63. Zimmerman GA, Mclntyre TM, Prescott SM. Thrombin stimulates the adherence of neutrophils to human endothelial cells in vitro. J Clin Investig. 1985;76(6):2235-46.

64. Prescott SM, Zimmerman GA, Mclntyre TM. Human endothelial cells in culture produce platelet-activating factor (1-alkyl-2-acetyl-sn-glycero-3phosphocholine) when stimulated with thrombin. Proc Natl Acad Sci USA. 1984;81(11):3534-8.

65. Levy JH, Tanaka KA. Inflammatory response to cardiopulmonary bypass. Ann Thorac Surg. 2003;75(2):S715-20.

66. Rahe-Meyer N, Solomon C, Tokuno ML, Winterhalter M, Shrestha M, Hahn A, Tanaka K. Comparative assessment of coagulation changes induced by two different types of heart-lung machine. Artif Organs. 2010;34(1):3-12. 
67. Fromes Y, Gaillard D, Ponzio O, Chauffert M, Gerhardt MF, Deleuze P, Bical $\mathrm{OM}$. Reduction of the inflammatory response following coronary bypass grafting with total minimal extracorporeal circulation. Eur J Cardiothorac Surg. 2002;22(4):527-33.

68. Cheung PY, Sawicki G, Salas E, Etches PC, Schulz R, Radomski MW. The mechanisms of platelet dysfunction during extracorporeal membrane oxygenation in critically ill neonates. Crit Care Med. 2000;28(7):2584-90.

69. Sims PJ, Wiedmer $T$. The response of human platelets to activated components of the complement system. Immunol Today. 1991;12(9):338-42.

70. Whiteheart SW. Platelet granules: surprise packages. Blood. 2011;118(5):1190-1.

71. Kraft F, Schmidt C, Van Aken H, Zarbock A. Inflammatory response and extracorporeal circulation. Best Pract Res Clin Anaesthesiol. 2015;29(2):113-23.

72. Rinder H, Bonan J, Rinder C, Ault K, Smith B. Activated and unactivated platelet adhesion to monocytes and neutrophils. Blood. 1991;78(7):1760-9.

73. Neumann FJ, Marx N, Gawaz M, Brand K, Ott I, Rokitta C, Sticherling C, Meinl C, May A, Schomig A. Induction of cytokine expression in leukocytes by binding of thrombin-stimulated platelets. Circulation. 1997;95(10):2387-94.

74. Maugeri N, Brambilla M, Camera M, Carbone A, Tremoli E, Donati MB, De Gaetano G, Cerletti C. Human polymorphonuclear leukocytes produce and express functional tissue factor upon stimulation1. J Thromb Haemost. 2006; 4(6):1323-30.

75. Dunkelberger JR, Song W-C. Complement and its role in innate and adaptive immune responses. Cell Res. 2009;20(1):34-50.

76. Ricklin D, Lambris JD. Complement in immune and inflammatory disorders: pathophysiological mechanisms. J Immunol. 2013;190(8):3831-8.

77. Nilsson B, Ekdahl KN, Mollnes TE, Lambris JD. The role of complement in biomaterial-induced inflammation. Mol Immunol. 2007;44(1-3):82-94.

78. Ascione R, Lloyd CT, Underwood MJ, Lotto AA, Pitsis AA, Angelini GD. Inflammatory response after coronary revascularization with or without cardiopulmonary bypass. Ann Thorac Surg. 2000;69(4):1198-204.

79. Johansson-Synnergren M, Nilsson F, Bengtsson A, Jeppsson A, Wiklund L. Off-pump CABG reduces complement activation but does not significantly affect peripheral endothelial function: a prospective randomized study. Scand Cardiovasc J. 2004:38(1):53-8.

80. Wehlin L, Vedin J, Vaage J, Lundahl J. Activation of complement and leukocyte receptors during on- and off pump coronary artery bypass surgery. Eur J Cardiothorac Surg. 2004;25(1):35-42.

81. Struber M, Cremer JT, Gohrbandt B, Hagl C, Jankowski M, Volker B, Ruckoldt $H$, Martin M, Haverich A. Human cytokine responses to coronary artery bypass grafting with and without cardiopulmonary bypass. Ann Thorac Surg. 1999;68(4):1330-5.

82. Lindholm L, Westerberg M, Bengtsson A, Ekroth R, Jensen E, Jeppsson A. A closed perfusion system with heparin coating and centrifugal pump improves cardiopulmonary bypass biocompatibility in elderly patients. Ann Thorac Surg. 2004;78(6):2131-8. discussion 2138.

83. Morgan IS, Codispoti M, Sanger K, Mankad PS. Superiority of centrifugal pump over roller pump in paediatric cardiac surgery: prospective randomised trial. Eur J Cardiothorac Surg. 1998;13(5):526-32.

84. Hein E, Munthe-Fog L, Thiara AS, Fiane AE, Mollnes TE, Garred P. Heparincoated cardiopulmonary bypass circuits selectively deplete the pattern recognition molecule ficolin-2 of the lectin complement pathway in vivo. Clin Exp Immunol. 2015;179(2):294-9.

85. Ware LB, Eisner MD, Thompson BT, Parsons PE, Matthay MA. Significance of von Willebrand factor in septic and nonseptic patients with acute lung injury. Am J Respir Crit Care Med. 2004;170(7):766-72.

86. Duffy MJ, Mullan BA, Craig TR, Shyamsundar M, MacSweeney RE, Thompson G, Stevenson M, McAuley DF. Impaired endothelium-dependent vasodilatation is a novel predictor of mortality in intensive care. Crit Care Med. 2011;39(4):629-35.

87. Boyle Jr EM, Pohlman TH, Johnson MC, Verrier ED. Endothelial cell injury in cardiovascular surgery: the systemic inflammatory response. Ann Thorac Surg. 1997;63(1):277-84.

88. Fischetti F, Tedesco F. Cross-talk between the complement system and endothelial cells in physiologic conditions and in vascular diseases. Autoimmunity. 2006;39(5):417-28.

89. Perkins GD, Nathani N, McAuley DF, Gao F, Thickett DR. In vitro and in vivo effects of salbutamol on neutrophil function in acute lung injury. Thorax. 2007;62(1):36-42.

90. Wachtfogel YT, Kucich U, Hack CE, Gluszko P, Niewiarowski S, Colman RW Edmunds Jr LH. Aprotinin inhibits the contact, neutrophil, and platelet activation systems during simulated extracorporeal perfusion. J Thorac Cardiovasc Surg. 1993;106(1):1-9. discussion 9-10.
91. Rinder CS, Rinder HM, Smith BR, Fitch JC, Smith MJ, Tracey JB, Matis LA, Squinto SP, Rollins SA. Blockade of C5a and C5b-9 generation inhibits leukocyte and platelet activation during extracorporeal circulation. J Clin Investig. 1995;96(3):1564-72.

92. Kruger P, Saffarzadeh M, Weber AN, Rieber N, Radsak M, von Bernuth H, Benarafa C, Roos D, Skokowa J, Hartl D. Neutrophils: Between host defence, immune modulation, and tissue injury. PLoS Pathog. 2015;11(3):e1004651.

93. Kotani N, Hashimoto H, Sessler DI, Muraoka M, Wang JS, O'Connor MF, Matsuki A. Neutrophil number and interleukin-8 and elastase concentrations in bronchoalveolar lavage fluid correlate with decreased arterial oxygenation after cardiopulmonary bypass. Anesth Analg. 2000;90(5):1046-51.

94. Brix-Christensen V, Tonnesen E, Hjortdal VE, Chew M, Flo C, Marqversen J, Hansen JF, Andersen NT, Ravn HB. Neutrophils and platelets accumulate in the heart, lungs, and kidneys after cardiopulmonary bypass in neonatal pigs. Crit Care Med. 2002;30(3):670-6.

95. Kiaii B, Fox S, Swinamer SA, Rayman R, Higgins J, Cleland A, Fernandes P, MacDonald J, Dobkowski WB, Stitt LW, et al. The early inflammatory response in a mini-cardiopulmonary bypass system: a prospective randomized study. Innovations (Phila). 2012;7(1):23-32.

96. Bergman P, Belboul A, Göran Friberg L, Al-Khaja N, Mellgren G, Roberts D. The effect of prolonged perfusion with a membrane oxygenator (PPMO) on white blood cells. Perfusion. 1994;9(1):35-40.

97. van Furth R. Human monocytes and cytokines. Res Immunol. 1998; 149(7-8):719-20.

98. Moore Jr FD, Socher SH, Davis C. Tumor necrosis factor and endotoxin can cause neutrophil activation through separate pathways. Arch Surg. 1991; 126(1):70-3.

99. Bradley JR. TNF-mediated inflammatory disease. J Pathol. 2008;214(2):149-60.

100. Jones SA, Hooriuchi S, Topley N, Yamamoto N, Fuller GM. The soluble interleukin 6 receptor: mechanisms of production and implications in disease. FASEB J. 2001;15(1):43-58.

101. Jialiang S, Juanhong S, Qiyi C, Wenkui Y, Changsheng H, Yimin H, Juanjuan $Z$, Tao G, Fengchan $X$, Jieshou L. In-line hemofiltration minimized extracorporeal membrane oxygenation-related inflammation in a porcine model. Perfusion. 2014;29(6):526-33.

102. Risnes I, Wagner K, Ueland T, Mollnes T, Aukrust P, Svennevig J. Interleukin-6 may predict survival in extracorporeal membrane oxygenation treatment. Perfusion. 2008;23(3):173-8.

103. Hong TH, Kuo SW, Hu FC, Ko WJ, Hsu LM, Huang SC, Yang YW, Yu SL, Chen YS. Do interleukin-10 and superoxide ions predict outcomes of cardiac extracorporeal membrane oxygenation patients? Antioxid Redox Signal. 2014:20(1):60-8.

104. Bartlett RH. ECMO: The next ten years. Egyptian J Crit Care Med. 2016;4(1):7-10.

105. Kenne E, Renné T. Factor XII: a drug target for safe interference with thrombosis and inflammation. Drug Discov Today. 2014;19(9):1459-64.

106. Pittenger MF, Mackay AM, Beck SC, Jaiswal RK, Douglas R, Mosca JD, Moorman MA, Simonetti DW, Craig S, Marshak DR. Multilineage potential of adult human mesenchymal stem cells. Science. 1999;284(5411):143-7.

107. Le Blanc K, Davies LC. Mesenchymal stromal cells and the innate immune response. Immunol Lett. 2015;168(2):140-6.

108. Qiang Y, Liang G, Yu L. Human amniotic mesenchymal stem cells alleviate lung injury induced by ischemia and reperfusion after cardiopulmonary bypass in dogs. Lab Invest. 2016;96(5):537-46.

109. Clive Landis R, Murkin JM, Stump DA, Baker RA, Arrowsmith JE, De Somer F, Dain SL, Dobkowski WB, Ellis JE, Falter F, et al. Consensus statement: minimal criteria for reporting the systemic inflammatory response to cardiopulmonary bypass. Heart Surg Forum. 2010;13(2):E116-23. 